DOI: 10.20472/IAC.2020.054.014

RENATA KALMAN

University of Szeged, Hungary

\title{
DO LAW STUDENTS RECOGNIZE THE INJUSTICES OF SOCIETY? CAN WE ACHIEVE THE SOCIAL GOALS OF CLINICAL LEGAL EDUCATION?
}

\begin{abstract}
:
Clinical Legal Education is an experimental way of teaching law. The methodology originates from the US, although it is already well-known in almost every continent thanks to different foundations (e.g. Ford Foundation) and those lawyers who did everything to make the spread of this way of teaching and learning easy.

Clinical Legal Education has two main purposes: social and educational. Educational goals include lawyering skills (e.g. documents drafting, communication with clients), professional responsibility, and growing legal knowledge. Social purpose comprises the promotion of social justice. Students provide legal advice to marginalized, under-represented clients (e.g. homeless, disabled, poor, drug-addicted people) what gives the importance and uniqueness of this teaching method.
\end{abstract}

Some legal clinic experts have the opinion that Clinical Legal Education could partly achieve its social goal in those countries, where students cannot represent their clients before a court or any other authorities. Vis-à-vis in the US, where students represent their clients before any authorities, in most European countries (Poland, Czech Republic, Hungary) they provide legal advice in a written way or they prepare their clients for a trial, hearing, mediation, etc.

In the last 3 years, I work as a Program Coordinator of the Legal Clinic of the University of Szeged Faculty of Law and Political Sciences. Simultaneously, my PhD research focuses on the theoretical background of Clinical Legal Education, and its implementation into practice. In the course of my research, I won a research grant from the Ministry of Justice of Hungary in 2019, which provided me an opportunity to conduct a comparative research at the Law School of the University of Toledo, USA. Therefore, I made a survey focusing on lawyering skills and the social purpose that can be achieved during legal clinic studies.

In my presentation, I will briefly introduce some of my research results regarding the empathy of the students and their perception of social injustices. Since my survey has a comparative focus, I will present the similarities and differences between Hungarian and American students.

\section{Keywords:}

Clinical Legal Education, social goal, US, Hungary, comparative research, survey

JEL Classification: K19 